\title{
An Evolving Research to Tackle Teaching and Learning Challenges during Differential Equations Course: A Combination of Non-routine Problems and Teacher Training
}

\author{
Aisha Bibi ${ }^{1,2^{\star}}$, Mushtaq Ahmad ${ }^{3}$, Wajeeha Shahid ${ }^{1}$, Sharifa NorulAkmar Syed Zamri ${ }^{2}$, \\ Nabeel Abdallah Mohammad Abedalaziz ${ }^{2}$ \\ ${ }^{1}$ Department of Education, National University of Modern Languages (NUML), Islamabad, PAKISTAN \\ ${ }^{2}$ Department of Mathematics \& Science Education, Faculty of Education, University of Malaya, 50603, Kuala Lumpur, MALAYSIA \\ ${ }^{3}$ Faculty of Engineering, University of Malaya, 50603, Kuala Lumpur, MALAYSIA \\ *CORRESPONDENCE: $\square$ aishabibi@numl.edu.pk
}

\begin{abstract}
Teaching and learning of differential equations (DEs) have a prominent role in all the fields of education. In spite of its prominence and frequent applications, teaching and learning of DEs is still considered as one of the most difficult, particularly at pre-university level. This is because, the topic of differential equation along with differentiation and integration is only introduced first time at the 12th year of study or at pre-university level, and the students have no previous knowledge and understandings of this topic. Therefore, the aim of current study is to determine whether teaching and learning of DEs is a challenging task and also, to find out the ways these challenges can be tackled to develop a better understanding for differential equations problem solving. Results showed that teaching and learning of differential equation is not only a difficult part of the mathematics as compared to algebra, trigonometry but also demand high level of conceptual understanding and special efforts for solving differential equation problem. Addition of non-routine problems has been found major factor to enhance teaching and learning. Teacher should also be properly equipped and trained, so that they may educate both routine and nonroutine differential equation problem.
\end{abstract}

Keywords: differential equation, mathematics education, non-routine problems, teacher training

\section{INTRODUCTION}

Differential equations (DEs) have an essential role in mathematics and remained a significant noteworthy pillar of calculus course for a long time. The idea and concept of DEs is not only employed for making mathematical models but also applied to interrelate them with the real-life problems (Arango, Gaviria, \& Valencia, 2015; Frejd \& Bergsten, 2016). Therefore, it provides an opportunity to articulate the application of phenomena from other disciplines of science and social science fields such as Physics, Biology, Astronomy, Commerce and Economics (Arslan, 2010a; Berresford \& Rockett, 2015; Rohde, Jain, Poddar, \& Ghosh, 2012). Hence, differential equation concept has been integrated in diverse courses of several sectors including college level (Blumenfeld, 2006; Singer, Ross, \& Jackson-Lee, 2016).

In developing countries, like Pakistan, differential equation's course, are commenced in the second year of secondary school. This course consists of ordinary differential equation-based problems and solving them for the general as well as particular solution. A typical calculus at secondary level or pre-university level course

Article History: Received 4 March $2019 \bullet$ Revised 1 May $2019 \bullet$ Accepted 2 May 2019

(C) 2019 by the authors; licensee Modestum Ltd., UK. Open Access terms of the Creative Commons Attribution 4.0 International License (http://creativecommons.org/licenses/by/4.0/) apply. The license permits unrestricted use, distribution, and reproduction in any medium, on the condition that users give exact credit to the original author(s) and the source, provide a link to the Creative Commons license, and indicate if they made any changes. 
incorporate following major topics; derivative part includes derivatives of polynomial, monotonic and composite functions, derivation of trigonometric, exponential and logarithmic functions along with the concept of stationary points. Beside this, second order derivatives are also used to differentiate maxima and minima. Second part includes the basics concepts of integration, properties of integral and its main theorem along with the concepts of integral of polynomials, trigonometric, exponential and rational functions. In addition, integration by parts and substitutions, improper integrals and convergence criteria are also incorporated to second part. In the third part, main topics are introduction of differential equation, formulation of the differential equation from a problem situation or from a graphical representation, problem solving for the particular and general solutions of differential equations. Students begins their university calculus courses by revisiting secondary school topics such as functions, limits and derivatives, differential equation, which mostly takes half a semester or considerable additional.

From the teaching point of view, exploring effective and innovative strategies for the teaching of a differential equation course had been remained a focus point in the field of mathematics education (McGinnis, Kramer, Shama, Graeber, Parker, \& Watanabe, 2002; Shulman, 2000; Vajravelu, 2018). Various options have been evaluated for differential equations course and also for addressing the concepts related to them (Raychaudhuri, 2008). Usually, three different approaches (algebraic, numerical and graphical) are employed to solve differential equations (Arslan, 2010b; Artigue, 1989). The reform movement in teaching and learning differential equation was stimulated in the mid-1980s due to increased accessibility of technology and by calculus reform. At higher levels of education, this moment yielded better results. However, at initial or pre university levels, it is still a great challenge to determine how students interact with the digital tools and representation registers associated with ordinary differential equations to give meaning to parameters associated with it (Rowland, 2006; Rowland \& Jovanoski, 2004), and how to develop instruction strategies to promote student learning (Rasmussen, 2001). Apart from these reforms, Cobb (1985) argued for the incorporation of students' belief systems, because there is a strong correlation between beliefs about mathematics and mathematical achievement (Beghetto \& Baxter, 2012; Schommer- Aikins, Duell, \& Hutter, 2005; Schommer-Aikins \& Duell, 2013). Likewise, McLeod (1992) had same opinion that mathematics beliefs enhance or weaken individual's mathematical and problem solving ability. Other researchers also supported these studies (Ahmed, Van der Werf, Kuyper, \& Minnaert, 2013; Ayebo \& Mrutu, 2019; Jäder, Sidenvall, \& Sumpter, 2017).

Non routine based problem solving were also considered as the important innovative strategy for teaching of a differential equation course (Khotimah \& Masduki, 2016; Lee \& Chen, 2009). It was observed that non routine problem utilized students' attention, effort and learning strategies to be solved because these problems are usually non-standard, involving unexpected and unfamiliar solutions (Polya, 1962; Rehman \& Masud, 2012). However, literature shows that in the developing countries, mostly teaching, assessments and exams are just focusing on routine-based problem solving such as calculating limits and derivatives and to solve differential equation, therefore, students considered it useful and just try to earn good marks. Due to this, transition from school to tertiary mathematics teaching and learning becomes more challenging and difficult in terms of real understandings and problem solving. In addition, it was noticed that even successful calculus students were unable to explain or solve non-routine problems (Dawkins \& Epperson, 2014). Therefore, most of the students avoid this essential part of mathematics, which leads to severe comprehension problems at higher levels of education where they correlate with real-life problems.

This work, particularly emphasized on the non-routine-based problem solving for teaching of a differential equation course. Beside this, current study also determines whether teaching and learning of DEs is a challenging task and to identify challenges and issues in differential equation problem. And also, to find out the ways these challenges can be tackled to develop a better understanding for differential equation problem solving. To assess these challenging factors influencing teaching and learning of DEs at pre-university level, the mathematicians, mathematics educators, and psychology expertise views and ideas were assessed.

\section{RESEARCH OBJECTIVES}

The aim of current article is to find out the challenging aspects that influence undergraduate student's differential equation problem solving ability. It is expected that outcomes and results claiming current study will help instructors and teachers for some adroit thoughts over the issues contemplated in the territory of differential equations. 
The scrutinize research questions addressed by this study are therefore:

1. Do teaching and learning of DEs is a challenging task at pre-university level?

2. Does non routine based problem-solving help in teaching a DEs course

3. How teaching and learning challenges of DEs can be tackled to develop a better understanding for problem solving?

\section{METHODOLOGY}

To assess key challenging factors influencing teaching and learning of DEs at pre-university level, the mathematicians, mathematics educators, and psychology expertise who taught in college and university were requested to fill self-developed questionnaire. Experts views and ideas were assessed with respect to different parameters, such as difficulties in teaching and learning of differential equation, prerequisite for high level of conceptual understanding, correlation of non-routine DEs to real world problems, addition of non-routine DEs and perceptions about the need of trained and skilled teachers.

\section{RESULTS AND DISCUSSIONS}

Experts opinion about "teaching and learning of differential equation as a difficult part of mathematics at inter-college level as compared to other parts like algebra, trigonometry, and etc." showed that overall 60 percent of the total experts were agreed from it that both teaching and learning of differential equation is a difficult part of the mathematics. Among these, 30 percent were agreed while 30 percent were strongly agreed with it. However, 40 percent of the total experts disagreed that teaching and learning of differential equation is a difficult part of the mathematics as compared to algebra, trigonometry. Interestingly, it was analyzed that participants having less experience and education level considered teaching and learning of differential equation as a difficult part while more experienced educators consider it as normal teaching. It might be due to excess training, experience or higher qualification (Schmidt, Burroughs, Cogan, \& Houang, 2017; Wagner, Speer, \& Rossa, 2007).

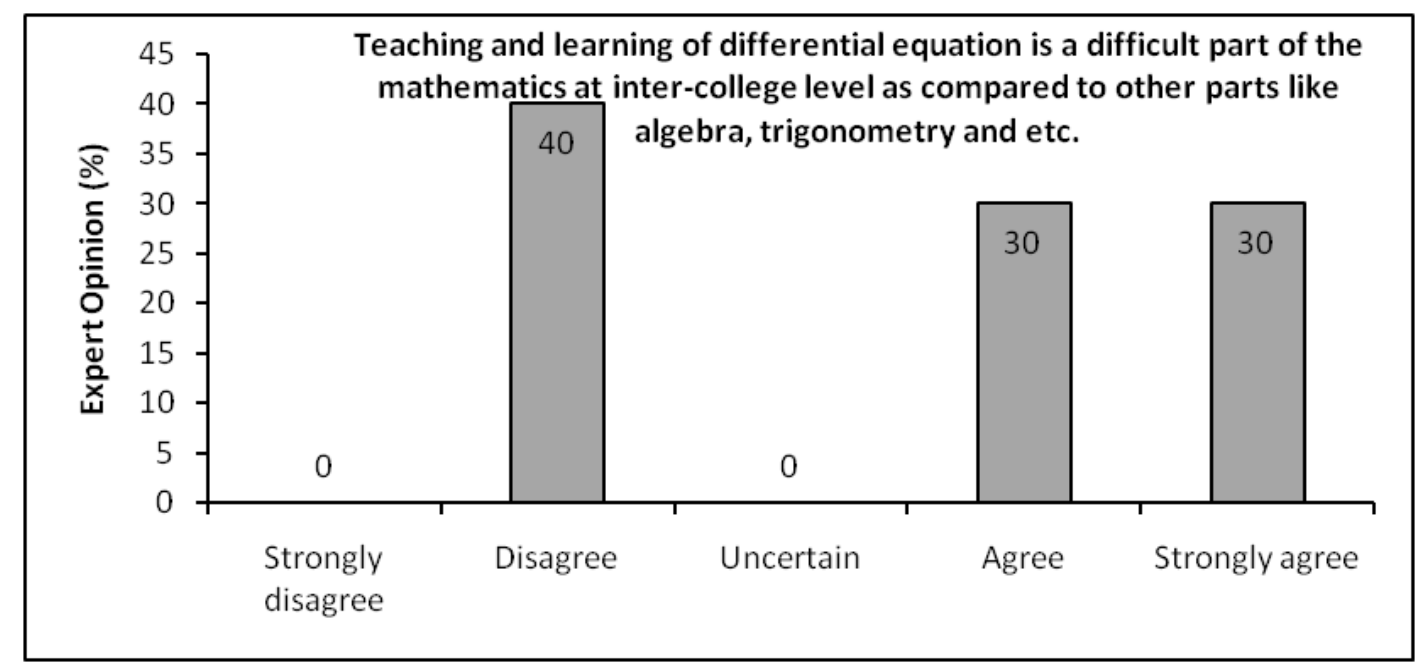

Figure 1. Teaching and learning is a difficult part of the mathematics

Conceptual understanding also effects both the teaching and learning of DEs therefore, experts were also asked that whether differential equation teaching and learning need high level of conceptual understanding and special efforts. Figure 2 shows that 90 percent were agreed, whereas 10 percent were strongly agreed that high level of conceptual understanding and special efforts is essential for differential equation problem solving. 


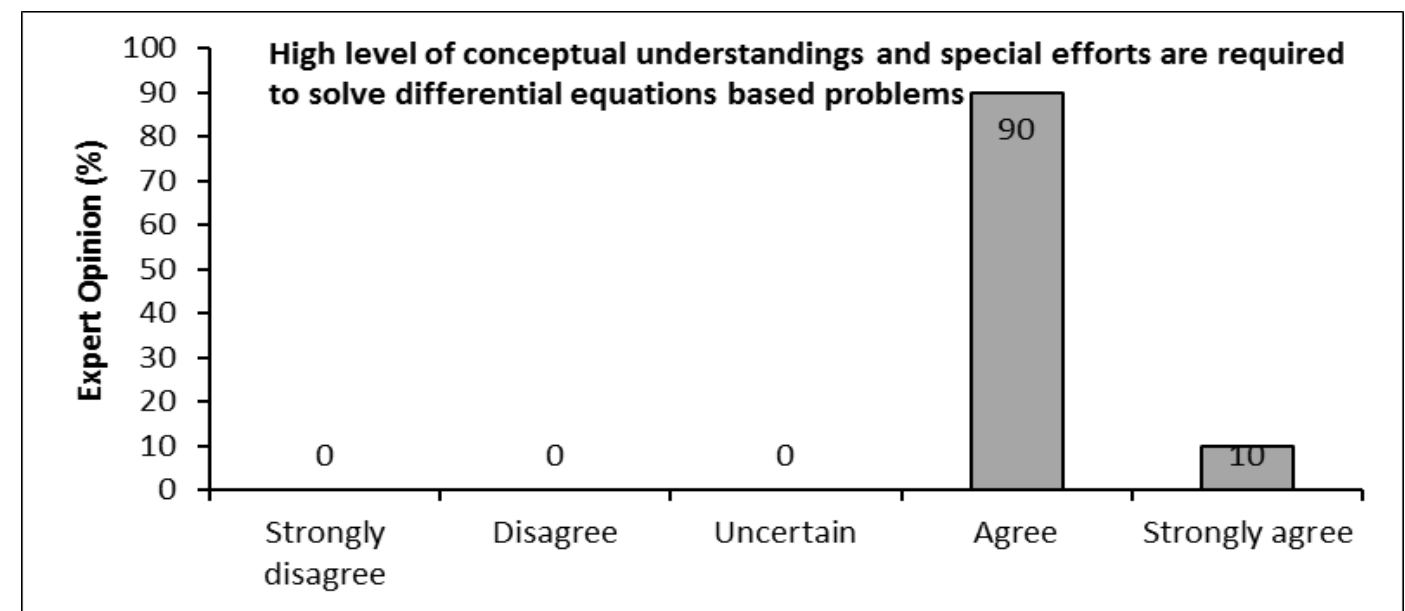

Figure 2. High level of conceptual understandings and special efforts are required to solve differential equations-based problems

Although, traditional methods of differential equation instruction just focus on procedural methods. Unfortunately, these methods did not encourage undergrads from creating their own strategies (Allen, 2006). Because, in a traditional differential equation environment, Selahattin (2010b) reported that nature of students' learning is procedural and is restricted to mastering and applying a few algebraic techniques. M Artigue, (1989) supported these results in a sense, so as to learner do not have understanding of differential equation concept (Boyce, 1994; Rasmussen, 2001). Literature also shows that usually deprived academic achievement results in calculus are caused by lack of conceptual understanding and inadequacy of teacher's content knowledge (Makgakga \& Makwakwa, 2016; Muzangwa \& Chifamba, 2012).

For conceptual understandings, solving a non-routine problem can also contribute to the mental development of a student. Because, non-routine based tasks require the problem solver to use their heuristic strategies to approach the problem, to understand it and proceed toward a suitable solution (Hesse, Care, Buder, Sassenberg, \& Griffin, 2015). Consequently, these non-routines-based tasks enhance student's higherorder thinking during evolution of understanding, analysis, exploration and application of mathematical concepts. Moreover, the application or correlation of non-routine differential equation in real world problem is also important for conceptual understanding (Szabo \& Andrews, 2017; Wijaya, van den Heuvel-Panhuizen, \& Doorman, 2015), therefore, this was also asked here particularly. In the response, 80 percent of experts were agreed with. Whereas, 10 percent expert were not sure about the correlation of non-routine differential equation in real world problem.

Although, non-routine differential equation problems are considered as difficult because, students' special attention, efforts and learning strategies are required to solve problems containing differential equations, particularly non-routine problems. The reason is that these problems are typically concerned with unanticipated, unusual, and strange solutions (Polya, 1962; Rehman \& Masud, 2012). Alas, these non-routine differential equation problems are avoided at inter level. Keeping in mind this perspective, expert's opinion regarding to the consideration of non-routine problems was asked. It was observed that 50 percent and 40 percent experts were agreed and strongly agreed with it that non-routine differential equation problems are less focused at inter level. However, only 10 percent experts were strongly disagreed with this statement. 


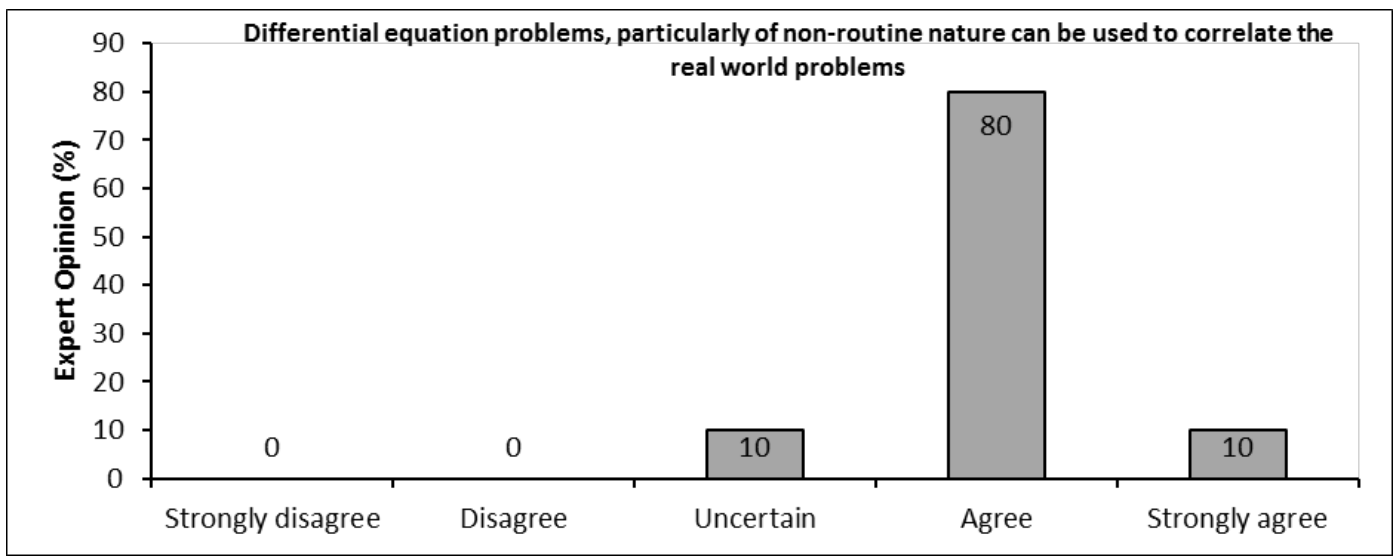

Figure 3. Differential equation problems, particularly of non-routine nature can be used to correlate the realworld problems

Literature shows that most of the researchers strongly emphasized on the addition and attainment of nonroutine problems in math curriculum, as they are appropriate for developing reasoning skills, attitudes and the capacity to apply these aptitudes over real life situations (Celebioglu, Yazgan, \& Ezentaş, 2010; Lee \& Chen, 2009; Yazgan, 2015, 2016). Celebioglu, Yazgan, and Ezentaş (2010) also supported the importance of non-routine strategies in math text books and math curriculum, and these researchers recommend that more non-routine strategies should be taught from the beginning of the first grade.

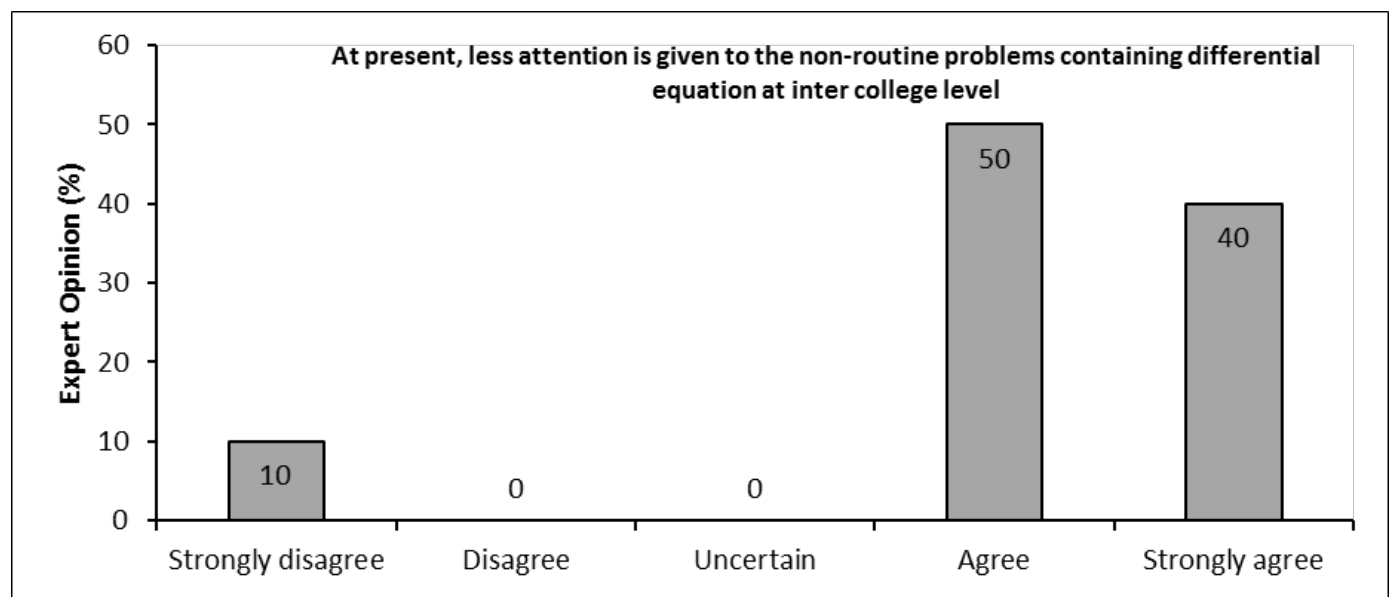

Figure 4. At present, less attention is given to the non-routine problems containing differential equation at inter college level

Keeping in mind, experts were further asked whether policy makers should add non-routine differential equation problems in new mathematics curriculum. Among all of the participants, 60 percent experts highly supported this statement. Interestingly, none of the participant opposed this idea. 


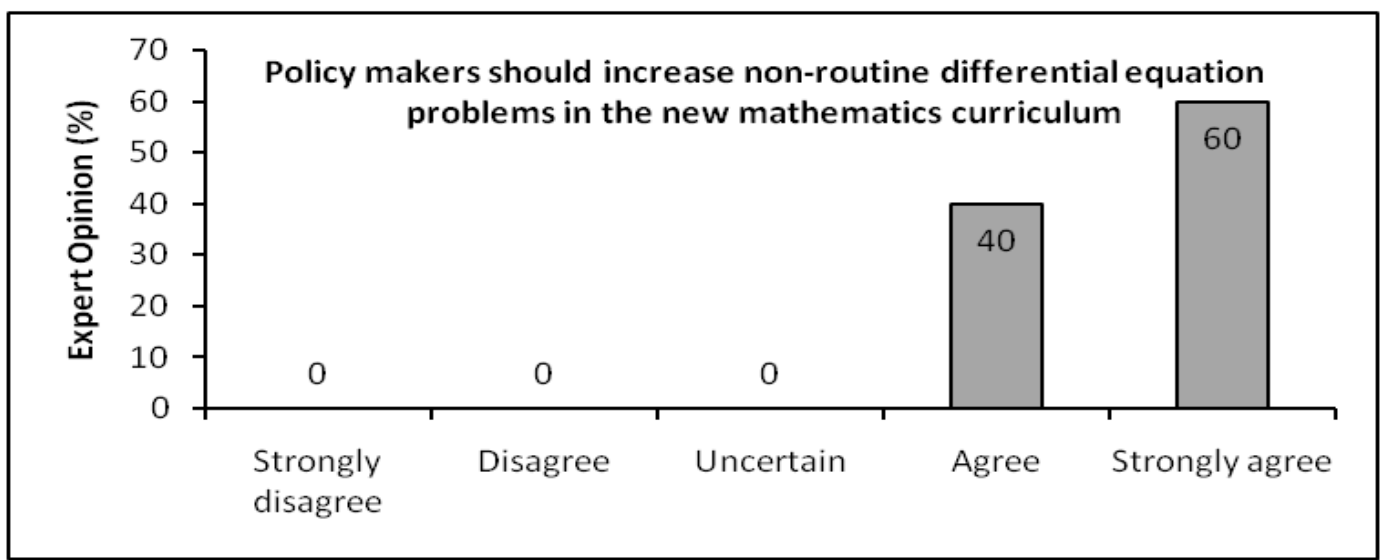

Figure 5. Policy makers should increase non-routine differential equation problems in mathematics curriculum

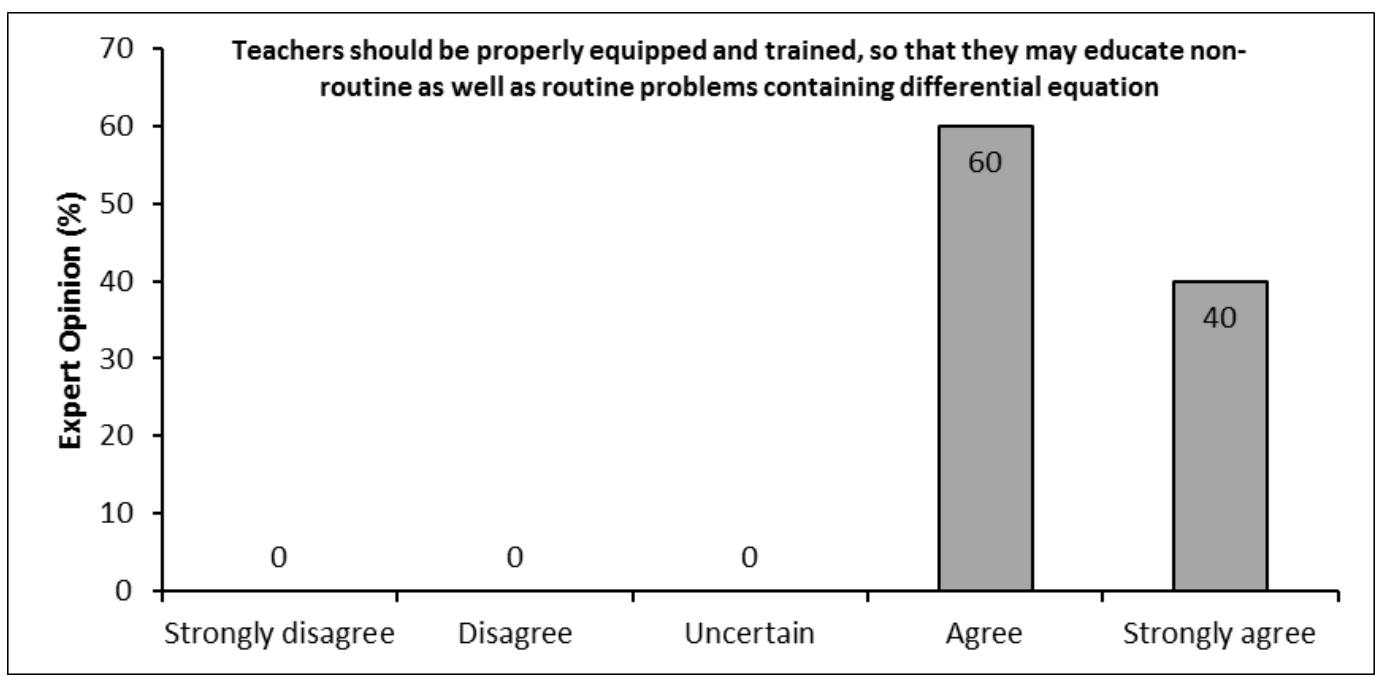

Figure 6. Teachers should be properly equipped and trained, so that they may educate non-routine as well as routine problems containing differential equation

Only addition of non-routine differential equation problem in mathematics curriculum is not enough. But teacher should be properly equipped and trained, so that they may educate both routine as well as non-routine differential equation problem. For this purpose, expert's opinion and concerned were important. Results showed that 60 percent were agreed with it. Moreover, 40 percent of the experts were strongly agreed that teacher should be properly equipped and trained, so that they may educate both routine as well as non-routine differential equation problem. Literature also supports this data (Lottero-Perdue \& Parry, 2017; Özsoy \& Ataman, 2017; Wagner, Speer, \& Rossa, 2007).

\section{DISCUSSIONS}

Taking constantly on these findings under account, a typical calculus at secondary course is expected to include: Applications of non-routine and real-life problems are rare in calculus secondary courses. More nonroutine DE problems and their applications of real life should be included. The exams could be divided into three parts; one emphasizes routine exercises, second that evaluate theoretical aspects of differential equation course, and final part should consider relate non-routine real problems.

These non-routine differential equation word problems, routine procedure should also be accompanied with graphs of the involved functions. For that reason, teachers must be facilitated with effective training, so that they may able to provide guidance to students during transition from algebraic to graphical mode or vice versa to avoid mistakes. Accessibility of computers labs can also overcome several issues of algebraic, graphical, 
numerical methods and their integration into a single approach for effective differential equation-based problem solving.

Besides course content, teaching style and instructional approaches, perceptions about mathematics and specific concept, learning strategies, purpose or goal of learning also affect teaching and learning mathematics (Biza, Giraldo, Hochmuth, Khakbaz, \& Rasmussen, 2016).

From teaching point of view, teachers should emphasize activities that encourage students to explore differential equation topics, develop and refine their own ideas, strategies, and technique. Furthermore, challenging activities should be created and avoid comparison among students. So that students can actively participate in the whole activity. The role of teacher should be a facilitator rather than a dispenser of information. Additionally, differential equation problem solving and reasoning should more emphasize at secondary school mathematics instead of rote manipulations section. For this purpose, connections, applications, verifications, and related differential equation problems must be given priority over rehearsing algorithms.

In addition to it, teachers must give attention to non-routine-based problems, related to some specific type and area to give students in-depth understandings. Also, these non-routine problems must be balanced with graphics of the involved functions to assess and enhance student's differential equation problem solving ability. They should educate and smartly trained their students during transition from algebraic to graphical mode or vice versa to avoid mistakes.

Furthermore, contextualizing learning using real world problems or authentic environment examples are also an important pillar in constructivist pedagogy (Abdulwahed, Jaworski, \& Crawford, 2012). In the developed countries, different methods including novel pedagogies (such as collaborative learning, inquiry/problems/discovery based learning), contextual problems, mathematical software packages (Mathematica, Maple), and online tools (Wikis and web based courses) are being used to facilitate conceptual understanding and constructivist mathematics learning (Abdulwahed, Jaworski, \& Crawford, 2012). Therefore, all these tacit should be employed to enhance conceptual understanding of DEs in developing countries such as Pakistan.

An alternative teaching approach is also needed so as to reduce traditional lecturing model. There may be a need to implement of flipped learning approach like (Oh Nam, 2015), in which short instructions are provided through videos and online courses. Whereas, class time is devoted for exercise, activities or discussion. Consequently, students assist their class mates in peer assisted learning environment (PAL) (Biza, Giraldo, Hochmuth, Khakbaz, \& Rasmussen, 2016). This will not only enhance their skills, also boost up their motivation as well as interest for differential equation problem solving.

\section{CONCLUSIONS}

In this work it was observed that teaching and learning of differential equation is not only a difficult part of the mathematics as compared to algebra, trigonometry but also demand high level of conceptual understanding and special efforts for solving differential equation problem. Addition of non-routine problems and teacher training program were been found major factors to enhance teaching and learning. The findings of present study had provided a few critical ramifications to the educational curriculum, instructive module designers and educators, particularly in mathematics and science education. The nature of the sample imposes limitations upon the findings and their generalization across all of Pakistan, however, the findings may provide directions both in implementation of teaching and learning, and curriculum aspects. Mathematics teachers can utilize the findings of current study in assessing the students' differential equation problem solving ability. In addition, teacher may apply these findings for assessing students' problem-solving ability in other parts of calculus or mathematics.

\section{Disclosure statement}

No potential conflict of interest was reported by the authors. 


\section{Notes on contributors}

Aisha Bibi - Department of Education, National University of Modern Languages (NUML), Islamabad, Pakistan and Department of Mathematics \& Science Education, Faculty of Education, University of Malaya, 50603, Kuala Lumpur, Malaysia.

Mushtaq Ahmad - Faculty of Engineering, University of Malaya, 50603, Kuala Lumpur, Malaysia.

Wajeeha Shahid - Department of Education, National University of Modern Languages (NUML), Islamabad, Pakistan.

Sharifa NorulAkmar Syed Zamri - Department of Mathematics \& Science Education, Faculty of Education, University of Malaya, 50603, Kuala Lumpur, Malaysia.

Nabeel Abdallah Mohammad Abedalaziz - Department of Mathematics \& Science Education, Faculty of Education, University of Malaya, 50603, Kuala Lumpur, Malaysia.

\section{REFERENCES}

Abdulwahed, M., Jaworski, B., \& Crawford, A. (2012). Innovative approaches to teaching mathematics in higher education: A review and critique. Nordic Studies in Mathematics Education, 17(2), 49-68.

Ahmed, W., Van der Werf, G., Kuyper, H., \& Minnaert, A. (2013). Emotions, self-regulated learning, and achievement in mathematics: A growth curve analysis. Journal of educational psychology, 105(1), 150. https://doi.org/10.1037/a0030160

Allen, K. S. (2006). Students' participation in a differential equations class: Parametric reasoning to understand systems. Purdue University.

Arango, J., Gaviria, D., \& Valencia, A. (2015). Differential calculus teaching through virtual learning objects in the field of management sciences. Procedia - Social and Behavioral Sciences, 176, 412-418. https://doi.org/10.1016/j.sbspro.2015.01.490

Arslan, S. (2010a). Do students really understand what an ordinary differential equation is? International Journal of Mathematical Education in Science and Technology, 41(7), 873-888. https://doi.org/10.1080/0020739X.2010.486448

Arslan, S. (2010b). Traditional instruction of differential equations and conceptual learning. Teaching Mathematics and its Applications, 29(2), 94-107. https://doi.org/10.1093/teamat/hrq001

Artigue, M. (1989). Une recherche d'ingenierie di-dactique sur l'enseignement des equations differentielles en premier cycle universitaire in equipe de didactique des mathematiques.

Ayebo, A., \& Mrutu, A. (2019). An exploration of calculus students' beliefs about mathematics. International Electronic Journal of Mathematics Education, 14(2), 385-392. https://oi.org/10.29333/iejme/5728

Beghetto, R. A., \& Baxter, J. A. (2012). Exploring student beliefs and understanding in elementary science and mathematics. Journal of Research in Science Teaching, 49(7), 942-960. https://doi.org/10.1002/tea.21018

Berresford, G. C., \& Rockett, A. M. (2015). Brief applied calculus: Nelson Education.

Biza, I., Giraldo, V., Hochmuth, R., Khakbaz, A., \& Rasmussen, C. (2016). Research on teaching and learning mathematics at the tertiary level: State-of-the-art and looking ahead Research on teaching and learning mathematics at the tertiary level (pp. 1-32): Springer, Cham. https://doi.org/10.1007/978-3-319-41814-8

Blumenfeld, H. L. (2006). Student's reinvention of straight-line solutions to systems of linear ordinary differential equations. San Diego State University. Retrieved from http://faculty.sdmiramar.edu/faculty/sdccd/hblumenf/thesis.pdf

Boyce, W. E. (1994). New directions in elementary differential equations. College Mathematics Journal, 25(5), 364-371. https://doi.org/10.1080/07468342.1994.11973640

Celebioglu, B., Yazgan, Y., \& Ezentaş, R. (2010). Usage of non-routine problem solving strategies at first grade level. Procedia - Social and Behavioral Sciences, 2(2), 2968-2974. https://doi.org/10.1016/j.sbspro.2010.03.449

Cobb, P. (1985). Two children's anticipations, beliefs, and motivations. Educational studies in mathematics, 16(2), 111-126. https://doi.org/10.1007/BF02400933 
Dawkins, P. C., \& Epperson, J. A. M. (2014). The development and nature of problem-solving among firstsemester calculus students. International Journal of Mathematical Education in Science and Technology, 45(6), 839-862. https://doi.org/10.1080/0020739X.2014.884645

Frejd, P., \& Bergsten, C. (2016). Mathematical modelling as a professional task. Educational studies in mathematics, 91(1), 11-35. https://doi.org/10.1007/s10649-015-9654-7

Hesse, F., Care, E., Buder, J., Sassenberg, K., \& Griffin, P. (2015). A framework for teachable collaborative problem solving skills Assessment and teaching of 21st century skills (pp. 37-56): Springer. https://doi.org/10.1007/978-94-017-9395-7_2

Jäder, J., Sidenvall, J., \& Sumpter, L. (2017). Students' mathematical reasoning and beliefs in non-routine task solving. International Journal of Science and Mathematics Education, 15(4), 759-776. https://doi.org/10.1007/s10763-016-9712-3

Khotimah, R. P., \& Masduki, M. (2016). Improving teaching quality and problem solving ability through contextual teaching and learning in differential equations: A lesson study approach. Journal of Research and Advances in Mathematics Education, 1(1), 13. https://doi.org/10.23917/jramathedu.v1i1.1791

Lee, C.-Y., \& Chen, M.-P. (2009). A computer game as a context for non-routine mathematical problem solving: The effects of type of question prompt and level of prior knowledge. Computers \& Education, 52(3), 530542. https://doi.org/10.1016/j.compedu.2008.10.008

Lottero-Perdue, P. S., \& Parry, E. A. (2017). Perspectives on failure in the classroom by elementary teachers new to teaching engineering. Journal of Pre-College Engineering Education Research (J-PEER), 7(1), 4. https://doi.org/10.7771/2157-9288.1158

Makgakga, S., \& Makwakwa, E. G. (2016). Exploring learners'difficulties in solving grade 12 differential calculus: A case study of one secondary school in polokwane district.

McGinnis, J. R., Kramer, S., Shama, G., Graeber, A. O., Parker, C. A., \& Watanabe, T. (2002). Undergraduates' attitudes and beliefs about subject matter and pedagogy measured periodically in a reform-based mathematics and science teacher preparation program. Journal of Research in Science Teaching, 39(8), 713-737. https://doi.org/10.1002/tea.10042

McLeod, D. B. (1992). Research on affect in mathematics education: A reconceptualization. Handbook of research on mathematics teaching and learning, 575-596.

Muzangwa, J., \& Chifamba, P. (2012). Analysis of errors and misconceptions in the learning of calculus by undergraduate students. Acta Didactica Napocensia, 5(2), 1-10. Retrieved from https://eric.ed.gov/?id=EJ1054301

Oh Nam, K. (2015). How to teach without teaching: An inquiry-oriented approach in tertiary education. Paper presented at the Proceedings of PME39 Hobart, Australia: PME.

Özsoy, G., \& Ataman, A. (2017). The effect of metacognitive strategy training on mathematical problem solving achievement. International Electronic Journal of Elementary Education, 1(2), 67-82.

Polya, G. (1962). Mathematical discovery: On understanding, teaching, and learning problem solving. New York: John Wiley.

Rasmussen, C. L. (2001). New directions in differential equations: A framework for interpreting students' understandings and difficulties. The Journal of Mathematical Behavior, 20(1), 55-87. https://doi.org/10.1016/S0732-3123(01)00062-1

Raychaudhuri, D. (2008). Dynamics of a definition: A framework to analyse student construction of the concept of solution to a differential equation. International Journal of Mathematical Education in Science and Technology, 39(2), 161-177. https://doi.org/10.1080/00207390701576874

Rehman, A.-u., \& Masud, T. (2012). Calculus and analytic geometry, mathematics 12. khyber pakhtunkhwa, Pakistan: Abbottabad Text Book Board

Rohde, U. L., Jain, G., Poddar, A. K., \& Ghosh, A. (2012). Introduction to integral calculus: Systematic studies with engineering applications for beginners: John Wiley \& Sons. https://doi.org/10.1002/9781118130346

Rowland, D. R. (2006). Student difficulties with units in differential equations in modelling contexts. International Journal of Mathematical Education in Science and Technology, 37(5), 553-558. https://doi.org/10.1080/00207390600597690 
Rowland, D. R., \& Jovanoski, Z. (2004). Student interpretations of the terms in first-order ordinary differential equations in modelling contexts. International Journal of Mathematical Education in Science and Technology, 35(4), 503-516. https://doi.org/10.1080/00207390410001686607

Schmidt, W. H., Burroughs, N. A., Cogan, L. S., \& Houang, R. T. (2017). The role of subject-matter content in teacher preparation: An international perspective for mathematics. Journal of Curriculum Studies, 49(2), 111-131. https://doi.org/10.1080/00220272.2016.1153153

Schommer- Aikins, M., Duell, O. K., \& Hutter, R. (2005). Epistemological beliefs, mathematical problemsolving beliefs, and academic performance of middle school students. The Elementary School Journal, 105(3), 289-304. https://doi.org/10.1086/428745

Schommer-Aikins, M., \& Duell, O. K. (2013). Domain specific and general epistemological beliefs their effects on mathematics.

Shulman, L. S. (2000). Teacher development: Roles of domain expertise and pedagogical knowledge. Journal of applied developmental psychology, 21(1), 129-135. https://doi.org/10.1016/S0193-3973(99)00057-X

Singer, J. E., Ross, J. M., \& Jackson-Lee, Y. (2016). Professional development for the integration of engineering in high school stem classrooms. Journal of Pre-College Engineering Education Research (J-PEER), 6(1), 3. https://doi.org/10.7771/2157-9288.1130

Szabo, A., \& Andrews, P. (2017). Uncovering the relationship between mathematical ability and problem solving performance of swedish upper secondary school students. Scandinavian Journal of Educational Research, 1-15. https://doi.org/10.1080/00313831.2016.1258671

Vajravelu, K. (2018). Innovative strategies for learning and teaching of large differential equations classes. International Electronic Journal of Mathematics Education, 13(2), 91-95. https://doi.org/10.12973/iejme/2699

Wagner, J. F., Speer, N. M., \& Rossa, B. (2007). Beyond mathematical content knowledge: A mathematician's knowledge needed for teaching an inquiry-oriented differential equations course. The Journal of Mathematical Behavior, 26(3), 247-266. https://doi.org/10.1016/j.jmathb.2007.09.002

Wijaya, A., van den Heuvel-Panhuizen, M., \& Doorman, M. (2015). Opportunity-to-learn context-based tasks provided by mathematics textbooks. Educational studies in mathematics, 89(1), 41-65. https://doi.org/10.1007/s10649-015-9595-1

Yazgan, Y. (2015). Sixth graders and non-routine problems: Which strategies are decisive for success? Educational Research and Reviews, 10(13), 1807-1816. https://doi.org/10.5897/ERR2015.2230

Yazgan, Y. (2016). Fourth graders and non-routine problems: Are strategies decisive for success? European Journal of Education Studies, 2(4), 100-120. 